\title{
DESCENTRALIZACIÓN Y DEMOCRACIA EN CHILE: ANÁLISIS SOBRE LA PARTICIPACIÓN CIUDADANA EN \\ EL PRESUPUESTO PARTICIPATIVO Y EL PLAN DE DESARROLLO COMUNAL
}

\author{
Egon Montecinos \\ UNIVERSIDAD DE LOS LAGOS, CHILE
}

\begin{abstract}
Resumen
Este estudio aporta evidencia al supuesto de que la profundización de la participación ciudadana en la gestión municipal no depende únicamente de mayores transferencias provistas por los niveles centrales de gobierno o de incentivos externos a nivel municipal, sino que también está relacionada con un cambio cualitativo en la forma de hacer gestión en el espacio local. Cuando este cambio se produce desde ese nivel, pueden lograrse iniciativas profundas de participación ciudadana. La estrategia metodológica utilizada fue un estudio comparado sobre la participación ciudadana que se produjo en los planes de desarrollo comunal y en los presupuestos participativos. Los casos seleccionados fueron Illapel, Cerro Navia, San Joaquín, Buin y Negrete.
\end{abstract}

Abstract

This paper contributes evidence to the premiss that the deepening of citizen participation in municipal management does not only depend on greater transfers from central government's levels or external incentives at municipal levels, but is also related to a qualitative change in municipal management in the local space. When this change takes place on a local level, deep initiatives of citizen participation can be achieved. The methodological strategy used was a comparative study on citizen participation in communal development plans and participatory budgets. The selected cases were Illapel, Cerro Navia, San Joaquín, Buin and Negrete.

PALABRAS CLAVE • Participación ciudadana • Gestión municipal • Descentralización

\section{INTRODUCCIÓN}

Entre los estudios sobre la dinámica política de la descentralización se pueden distinguir dos tendencias que se plantean diferentes preguntas e hipótesis de investigación. Por un lado, están los que abordan las causas que promueven la adopción de políticas descentralizadoras en América Latina, qué la provoca, cuándo y por qué (Mardones, 2006: 3). En este grupo, de acuerdo con Mardones (2006: 4), se encuentran las investigaciones asociadas a las hipótesis sobre democratización, estrategia electoral y top down ${ }^{1}$. Por otro lado, se encuentran los 
estudios que abordan las consecuencias del proceso descentralizador, o dicho de otra forma, el desempeño que adquieren las instituciones locales posterior a la instauración de las reformas de descentralización².

En estos últimos estudios se pueden distinguir dos preocupaciones fundamentales. La primera asociada al desempeño fiscal de los gobiernos subnacionales y en ella la pregunta fundamental es si la descentralización ha logrado mejorar el desempeño de las " 3 E" en el nivel local (eficiencia, economía y eficacia) y si eso ha conseguido disminuir las inequidades territoriales, o las han acrecentado y empoderado a caciques locales ${ }^{3}$. La segunda preocupación está dada por la contribución de la descentralización al fortalecimiento democrático de las sociedades latinoamericanas; la pregunta fundamental de esta tendencia es cómo las transferencias políticas, fiscales y administrativas, y en general la ampliación de actores locales en la decisión pública, han contribuido al fortalecimiento democrático de las sociedades locales a través de la profundización de la participación ciudadana en la gestión municipal, o contrariamente han provocado un efecto adverso ${ }^{4}$.

De ambas preocupaciones se pueden desprender dos hipótesis sobre el desempeño eficiente y democrático de la descentralización en las instituciones políticas locales. La primera hace alusión a que el "uso eficiente y democrático de la descentralización en el nivel local" está determinado por una reforma gerencialista nacional en los aparatos burocráticos municipales que permita evitar la captura de los recursos transferidos por parte de caciques locales (Finot, 2001; García Guadilla, 2002; Nickson, 2003).

La segunda hipótesis está dada por una estrategia más ciudadana y señala que el "uso eficiente y democrático de la descentralización" en los niveles locales se alcanzará mediante el empoderamiento ciudadano y/o de la sociedad civil, quienes deben controlar a la burocracia local y los caciques locales, actores que pueden verse fortalecidos producto de los procesos de descentralización en desmedro de la sociedad civil y de la democratización de los espacios locales (Delamaza, 2004; Huerta, 2000; Finot 1998, 1999 y 2003).

En Chile, el debate político sobre el desempeño eficiente y democrático de las instituciones locales se ha orientado mayoritariamente por la primera hipótesis y por el supuesto normativo de que para que la descentralización promueva procesos de participación ciudadana se requiere primero de una burocracia pública municipal profesionalizada y con vocación "gerencialista" que haga buen uso de los recursos y atribuciones descentralizadas ${ }^{5}$.

Esta idea supone que el componente de participación ciudadana en la gestión municipal es un proceso que puede ser inducido desde arriba y por medio de diseños institucionales con vocación

2 Esta separación entre los estudios de descentralización que abordan las causas y otros que ahondan en el desempeño de la descentralización no es exhaustiva, ya que no implica que una investigación que pone énfasis en esto último se desentienda de alguna de las hipótesis que explican la adopción de la descentralización en América Latina.

3 Parte de esta discusión se puede encontrar en Nickson, 1998 y 2003; Bardhan, 2002; Garcia Guadilla, 2002; Finot, 1998, 1999, 2001 y 2003; Carrillo, 2003; Huerta, 2000. Para profundizar en ello ver, Montecinos, 2005.

4 Igualmente, sobre este punto se recomienda ver, Finot, 1998 y 2001; Garcia Guadilla, 2002; Nickson, 2003 y 1998 ; Huerta, et al., 2000.

5 Este supuesto normativo transformado en reforma municipal se puede ver reflejado en las dos versiones del Programa de Fortalecimiento Institucional Municipal, PROFIM, impulsado por la Subsecretaría de Desarrollo Regional a partir del año 1994 (Subdere, 1999). 
gerencialista. Desde esta perspectiva, en los actores políticos locales y municipales se puede apreciar un discurso que plantea la necesidad imperiosa de impulsar políticas más profundas de descentralización (política, fiscal, y administrativa) como una condición necesaria para desatar un desempeño municipal más eficiente y con más y mejores prácticas participativas en la gestión local (Asociación Chilena de Municipalidades, 2006)

A este debate se espera contribuir con los resultados de esta investigación, relativizando esta tendencia normativa de la elite política chilena que plantea que con más atribuciones fiscales, políticas y administrativas en los niveles municipales, se provocarán más y mejores procesos de participación ciudadana.

En este estudio se plantea la tesis de que la profundización de la participación ciudadana -que debiera traer consigo la instauración de los procesos descentralizadores- no depende únicamente de mayores transferencias provistas por los niveles centrales de gobierno, sino que está relacionada con un cambio cualitativo en la forma de hacer gestión municipal y que este cambio nace esencialmente en el espacio local ${ }^{7}$. Este cambio cualitativo hace hincapié en que la gestión municipal participativa es un proceso esencialmente local, político y endógeno, donde el municipio cumple un rol de mediador y articulador de actores locales y no necesariamente gerencial y directivo. Este rol político del municipio y la generación de profundos procesos de participación ciudadana se pueden alcanzar aún teniendo como obstaculizador la herencia institucional centralista del Estado chileno.

\section{EL LUGAR DE LA PARTICIPACIÓN CIUDADANA EN LOS PROCESOS DE MODERNIZACIÓN MUNICIPAL}

La participación ciudadana, como ingrediente fundamental de una gestión pública democrática, aparece en Chile a comienzos de los años noventa como componente esencial de la descentralización y la modernización del Estado para alcanzar dos objetivos fundamentales: hacer más eficientes los servicios públicos y fortalecer la democracia por medio de una gestión pública participativa (Waissbluth, 2005: 49; Ramírez, 2001: 22; Comité Interministerial, 2000: 16).

Los municipios no escaparon a estos objetivos y a partir de 1994 la Subsecretaría de Desarrollo Regional y Administrativo inició el Programa de Fortalecimiento Institucional Municipal ${ }^{8}$ (PROFIM),

$6 \quad$ Esta idea o discurso se ve plasmado en las demandas planteadas por la asociación Chilena de Municipalidades a través de la revista Municipio Autónomo, número 11, noviembre de 2005 y en la Comisión de Reforma Municipal recientemente constituida e integrada por los diferentes sectores políticos que constituyen la Asociación Chilena de Municipalidades (Asociación Chilena de Municipalidades, 2005, ver www.munitel.cl).

$7 \quad$ Esta idea puede encontrar su principales detractores en quienes, inspirados en la discrecionalidad de los alcaldes para iniciar procesos de participación ciudadana (discrecionalidad que ofrece el propio diseño institucional), señalan que ésta debe ser una "cuestión de Estado" y no estar sujeta a la voluntad política de los alcaldes, y que, por tanto, debe legislarse para incluir aspectos relativos a la materia. Entre otros actores, quien sostiene esta idea es la Presidenta de la República, quien dentro de sus compromisos de campaña señaló que los espacios de participación ciudadana dependen en exceso de la voluntad política de los alcaldes (Asociación Chilena de Municipalidades, 2005).

8 El PROFIM, financiado por el Banco Mundial, formó parte de las medidas de modernización municipal impulsadas por el Gobierno de Chile a partir de 1994. El objetivo fundamental fue mejorar la gestión de servicios de las municipalidades y fortalecer los instrumentos de planificación para la toma de decisiones (Subdere, 1999). 
con el objetivo de incorporar nuevas tecnologías y fortalecer los instrumentos de planificación local, entre ellos, el Plan de Desarrollo Comunal (PLADECO) ${ }^{9}$.

A más de 11 años de iniciado este proceso de modernización municipal por medio del PROFIM, los diagnósticos realizados por el gobierno y por organismos no gubernamentales coinciden en que el desempeño municipal se ha mejorado parcialmente en las áreas operativas de la gestión, es decir, eficacia y eficiencia de la prestación de los servicios públicos (Delamaza et al., 2004: 48; Subdere, 2003: 50; Márquez et al., 2003: 21; Huerta et al., 2000: 20). También hay coincidencia en que el fortalecimiento democrático, entendido como un estilo de gestión participativo que implique consulta, control y fiscalización ciudadanía sobre la gestión municipal, todavía es muy incipiente en los instrumentos de planificación y no registra mayores avances sustantivos (Delamaza et al, 2004: 48; Subdere, 2003: 50; Márquez et al., 2001: 21; Huerta et al., 2000: 20).

No obstante este diagnóstico, a partir del año 2002 ha comenzado a aparecer experiencias de presupuestos participativos ${ }^{10}$, sin incentivos del gobierno central, que hacen presumir que a través de este instrumento de panificación se están abriendo nuevos espacios de participación en la gestión local chilena.

De ahí el objetivo de conocer para el caso chileno las características de la participación ciudadana que se produce en los tradicionales PLADECO, instrumentos de planificación exigidos por ley, con la participación ciudadana que se produce en los emergentes casos de presupuestos participativos. La comparación puede ayudar a precisar características y los factores que estarían determinando la participación ciudadana en los últimos y si ello tiene relación con aspectos institucionales o de otra naturaleza. De esta manera, las preguntas específicas que este estudio aborda son: ¿Existen diferencias sustantivas entre la participación ciudadana que se produce en el PLADECO y la que se produce en el presupuesto participativo? ¿De qué naturaleza son los factores que explican la participación ciudadana en los presupuestos participativos de la gestión municipal chilena?

Para abordar estas interrogantes el trabajo se presenta en cuatro partes. En la primera se da a conocer la estrategia metodológica utilizada. En la segunda se describen los antecedentes generales de los casos seleccionados. En la tercera se caracteriza el tipo de participación ciudadana que se manifestó en el PLADECO y en el presupuesto participativo. En el siguiente apartado se analizan los factores que determinaron el surgimiento de la participación ciudadana en los presupuestos participativos y, finalmente, se cierra el artículo con algunas conclusiones.

De acuerdo con el artículo 3 y 7 de la Ley 18.695, orgánica constitucional de municipalidades, le corresponde a las municipalidades la elaboración del PLADECO, el cual es el instrumento rector del desarrollo en la comuna. El PLADECO es el único de los tres instrumentos de planificación existentes en la gestión municipal chilena, los otros son el plan regulador y el presupuesto municipal, que para su elaboración, por ley y de acuerdo al artículo 7 de la Ley 18.695, debe considerar la participación ciudadana (Subdere, 2002).

10 La principal contribución que se espera hacer con este trabajo es entregar una primera aproximación empírica de la participación ciudadana en los casos chilenos de presupuesto participativo. Este artículo no pretende explicar la participación ciudadana en los presupuestos participativos chilenos a partir de las experiencias de casos como los de Brasil, Uruguay, Argentina, México o Perú. Con esto se espera aportar empíricamente a la escasa literatura chilena que aborda los presupuestos participativos, a diferencia de la que existe para América Latina. Al respecto se pueden citar estudios como los de Ismael Blanco y Ricard Gomá (2002a y 2002b); Nelson Chak Yalta (2005); Yves Sintomer (2005); William Nylen (2002 y 2003); Domingo Matías (2004). 


\section{METODOLOGÍA}

Este estudio plantea la hipótesis de que la participación ciudadana -entendida como el proceso de incidencia de ciudadanos en las decisiones públicas municipales, que puede ir desde la definición de proyectos hasta la fiscalización de la gestión de esos proyectos- en los presupuestos participativos es un proceso que se detona por aspectos esencialmente locales y endógenos y no dependen exclusivamente de factores institucionales como, por ejemplo, mayores atribuciones políticas, fiscales y administrativas hacia los municipios. La diferencia estará determinada por aspectos asociados a una gestión municipal endógena/local, relacional y facilitadora. Endógena, en el sentido que el instrumento de planificación surge por iniciativa de algún actor local y no necesariamente es originada por incentivos externos e institucionales. Relacional, porque articula a través de un rol municipal mediador a los actores políticos y burocráticos con los actores sociales, desde el proceso de definición de prioridades hasta la fiscalización de la gestión municipal. Facilitador, ya que genera las condiciones y espacios para la articulación de estos actores y facilita la participación de ellos desde la definición de proyectos hasta el control de ellos.

La estrategia metodológica utilizada fue un estudio comparado subnacional donde se seleccionaron municipios que han implementado conjuntamente presupuesto participativo y PLADECO. Los criterios de selección fueron los siguientes: a) Municipios que implementaron conjuntamente presupuesto participativo y PLADECO; b) Municipios con experiencias de presupuesto participativo funcionando durante un mínimo de dos años; c) Municipios con presupuesto participativo que hayan sido premiados por algún organismo gubernamental o no gubernamental ${ }^{11}$; d) Municipios con presupuesto participativo y que hayan implementado su PLADECO desde el año 2000 en adelante. Con estos criterios se seleccionaron los casos de Illapel, Buin, Negrete, Cerro Navia y San Joaquín. En estos municipios se compararon dos variables: Participación ciudadana en la gestión municipal y Rol político del municipio ${ }^{12}$.

\section{DESCRIPCIÓN DEMOGRÁFICA, FINANCIERA, SOCIAL Y POLÍTICA DE LOS CASOS}

Como se puede apreciar en la tabla 1, Cerro Navia y San Joaquín son municipios esencialmente urbanos, en los tres restantes hay un porcentaje relevante de ruralidad (15\%, 28\% y 38\%), se trata de los municipios de Buin en la Región Metropolitana, Illapel en la IV Región y Negrete en la VIII Región y que presenta el porcentaje más alto de ruralidad.

11 Este criterio se utilizó para cuidar la sustentabilidad de la experiencia, ya que han existido otras iniciativas de presupuesto participativo que no han perdurado en el tiempo (por ejemplo, Puerto Montt y Lanco). Como referencia se tomaron los dos premios a la innovación municipal existentes en Chile. El premio de la Corporación Innovación Ciudadana y el premio de Buenas Prácticas Municipales que entrega la Subdere.

12 "Participación ciudadana en la gestión municipal" se operacionalizó como aquella participación que puede presentarse desde el momento de la definición de las necesidades y prioridades a través de un diagnóstico comunal, hasta el momento del control de la implementación de esas prioridades por medio de la fiscalización ciudadana, ya sea a través de comités o asambleas de fiscalización. "Rol político del municipio" se operacionalizó como aquella función que cumple el municipio en el sentido de articular a los actores políticos (alcalde y concejales), y burocráticos (funcionarios municipales) con los actores sociales (organizaciones sociales y ciudadanos), desde el proceso de definición de necesidades hasta la fiscalización de la gestión municipal, a través de un rol municipal mediador y no directivo. 
En cuanto a la cantidad de habitantes, Cerro Navia y San Joaquín, se ubican como los municipios con mayor cantidad de población. Buin se puede clasificar como un municipio intermedio, y Negrete e Illapel se pueden agrupar en la categoría de municipios pequeños.

TABLA 1: Antecedentes demográficos

\begin{tabular}{lrccl}
\hline & $\begin{array}{c}\text { Población } \\
\text { Total }\end{array}$ & $\begin{array}{c}\text { Población } \\
\text { Urbana }\end{array}$ & $\begin{array}{c}\text { Población } \\
\text { rural }\end{array}$ & Región \\
\hline Cerro Navia & 148.312 & $100 \%$ & 0 & Metropolitana \\
San Joaquín & 97.625 & $100 \%$ & 0 & Metropolitana \\
Buin & 63.419 & $84 \%$ & $16 \%$ & Metropolitana \\
Illapel & 30.355 & $72 \%$ & $28 \%$ & Cuarta región \\
Negrete & 8.579 & $62 \%$ & $38 \%$ & Octava región \\
\hline
\end{tabular}

Fuente: Elaboración propia a base de la siguiente fuente consultada: SINIM (Sistema Nacional de Indicadores Municipales).

En cuanto a los indicadores de pobreza, los casos de Negrete e Illapel presentan los indicadores de pobreza más altos, con porcentajes que superan el $25 \%$, indicador que se ubica muy por sobre la media nacional de pobreza comunal. Por su parte, Buin y Cerro Navia tienen indicadores de pobreza levemente ubicados bajo la media nacional. San Joaquín es el municipio que presenta el indicador más bajo de pobreza en relación a la media nacional (tabla 2).

TABLA 2: Antecedentes de pobreza

\begin{tabular}{lcc}
\hline & Porcentaje de Pobreza & Promedio Nacional de Pobreza \\
\hline Negrete & $29,42 \%$ & $17,30 \%$ \\
Illapel & $26,66 \%$ & $17,30 \%$ \\
Buin & $16,24 \%$ & $17,30 \%$ \\
Cerro Navia & $16,01 \%$ & $17,30 \%$ \\
San Joaquín & $12,03 \%$ & $17,30 \%$ \\
\hline
\end{tabular}

Fuente: Elaboración propia a base de las siguientes fuentes consultadas: SINIM (Sistema Nacional de Indicadores Municipales).

Con relación a los antecedentes financieros, en la tabla 3 se observa que los casos de Cerro Navia y San Joaquín cuentan con un presupuesto municipal alto, ya que cada uno de sus presupuestos supera el promedio nacional de presupuesto municipal. Buin tiene un presupuesto que se ubica justo en la media nacional. Asimismo, Illapel y Negrete cuentan con un presupuesto municipal bajo el promedio nacional.

En la misma tabla, se observa que los casos de Cerro Navia, San Joaquín y Buin, cuentan con una dotación de funcionarios municipales que se encuentra por sobre la media nacional. Por su parte, los municipios de Illapel y Negrete cuentan con dotaciones de funcionarios municipales por debajo del promedio nacional. 
TABLA 3: Antecedentes financieros y de recursos humanos

\begin{tabular}{lcccc}
\hline & $\begin{array}{c}\text { Presupuesto } \\
\text { municipal }\end{array}$ & $\begin{array}{c}\text { Promedio nacional } \\
\text { de presupuesto } \\
\text { municipal }\end{array}$ & $\begin{array}{c}\text { Funcionarios } \\
\text { municipales } \\
\text { permanentes }\end{array}$ & $\begin{array}{c}\text { Promedio nacional de } \\
\text { funcionarios } \\
\text { municipales }\end{array}$ \\
\hline Cerro Navia & 9.710 .245 & 3.522 .133 & 255 & 117 \\
San Joaquín & 5.770 .976 & 3.522 .133 & 265 & 117 \\
Buin & 3.595 .458 & 3.522 .133 & 119 & 117 \\
Illapel & 1.953 .147 & 3.522 .133 & 60 & 117 \\
Negrete & 1.162 .911 & 3.522 .133 & 29 & 117 \\
\hline
\end{tabular}

Fuente: Elaboración propia a base de la siguiente fuente: SINIM (Sistema Nacional de Indicadores Municipales).

En cuanto al monto y porcentaje de inversión destinados a presupuesto participativo, se puede indicar que, en relación al presupuesto municipal total, la inversión destinada en promedio no supera el 3,2\% (tabla 4). Esto debido a que los municipios chilenos destinan un porcentaje muy elevado de su presupuesto a gastos corrientes ${ }^{13} y$, por el contrario, un reducido monto a inversión a la comunidad ${ }^{14}$. De este último ítem surge el dinero para destinar a presupuestos participativos. Se puede apreciar que los municipios pequeños y que cuentan con menor presupuesto municipal son los que destinan en proporción un porcentaje mayor a inversión participativa.

TABLA 4: Monto y porcentaje destinado a Presupuesto Participativo

\begin{tabular}{lccc}
\hline & Presupuesto municipal & $\begin{array}{c}\text { Monto a inversión en } \\
\text { presupuesto participativo }\end{array}$ & $\begin{array}{c}\text { Porcentaje de inversión } \\
\text { en relación } \\
\text { al presupuesto total }\end{array}$ \\
\hline Cerro Navia & 9.710 .245 .000 & 300.000 .000 & $3,08 \%$ \\
San Joaquín & 5.770 .976 .000 & 120.000 .000 & $2,07 \%$ \\
Buin & 3.595 .458 .000 & 118.000 .000 & $3,28 \%$ \\
Illapel & 1.953 .147 .000 & no predetermina monto & No destina monto \\
Negrete & 1.162 .911 .000 & 50.000 .000 & $4,30 \%$ \\
\hline
\end{tabular}

Fuente: Elaboración propia a base de las siguientes fuentes consultadas: SINIM (Sistema Nacional de Indicadores Municipales).

Respecto a los antecedentes políticos, los cinco alcaldes que implementaron presupuesto participativo pertenecen a algún partido de la coalición de centro-izquierda "Concertación de Partidos por la Democracia". Dentro de esta coalición, sólo dos son los partidos políticos que cuentan con

13 Los gastos corrientes son los gastos en personal y en bienes y servicios de consumo, en promedio los municipios chilenos destinan casi un 70\% de su presupuesto a este ítem (Gonzalo Frei, 2005).

14 El ítem inversión a la comunidad corresponde a los gastos destinados a ejecutar proyectos que promuevan el adelanto y el desarrollo local, este tipo de proyectos abarca diversas áreas, como sedes comunitarias, infraestructura, atención de menores, entre otros. En promedio, los municipios chilenos destinan entre un 8 y $12 \%$ de su presupuesto a este ítem (Gonzalo Frei, 2005). 
casos de presupuestos participativos, el Partido Socialista (PS) y el Partido Por la Democracia (PPD). Ambos partidos se enmarcan dentro de la corriente "progresista" de la Concertación. Este predominio también se mantiene en la distribución de los concejales, con la excepción de Negrete donde están empatados.

TABLA 5: Antecedentes políticos

\begin{tabular}{lcc}
\hline Municipio & Partido político del alcalde & Composición del concejo municipal \\
\hline Buin & PPD (Concertación) & Mayoría concertación \\
Cerro Navia & PPD (Concertación) & Mayoría concertación \\
San Joaquín & PPD (Concertación) & Mayoría concertación \\
Negrete & PS (Concertación) & Empate entre concertación y Alianza \\
Illapel & PS (Concertación) & Mayoría concertación \\
\hline
\end{tabular}

Fuente: Elaboración propia a base de la siguiente fuente: SINIM (Sistema Nacional de Indicadores Municipales)

\section{CARACTERIZACIÓN DE LA PARTICIPACIÓN CIUDADANA EN EL PLADECO Y EN LOS PRESUPUESTOS PARTICIPATIVOS}

\section{Participación ciudadana en el PLADECO}

En los cinco casos de elaboración de PLADECO predominó un estilo de participación ciudadana concentrado en el intercambio de información entre funcionarios municipales y dirigentes sociales para la configuración de un diagnóstico comunal (Torres, 2005). Las cinco municipalidades realizaron consultas -a través de encuestas o asambleas consultivas- a los dirigentes sociales para identificar las principales necesidades y carencias de la comunidad (Salinas, 2005; Díaz, Claudia, 2005; Sánchez, 2005; Maluenda, 2005; Gálvez, 2005). Luego de ello, el equipo técnico municipal realizó un diagnostico comunal, una priorización de necesidades y un fundamento técnico de los proyectos a ejecutar en un periodo de cuatro años (Torres, 2005). Este tipo de participación ciudadana en el PLADECO se puede definir como una participación ciudadana consultiva.

Las ideas que predominaron en la implementación del PLADECO fueron escuchar y consultar para diagnosticar las necesidades de la comunidad. Esta situación promovió un tipo de participación para involucrar a dirigentes sociales en la etapa de diagnóstico a través de la consulta ciudadana (Torres, 2005).

En ninguno de los casos de PLADECO los dirigentes sociales intervinieron en el proceso posterior al diagnóstico comunal como, por ejemplo, en el control y seguimiento de los proyectos que surgieron en él; "esta función fiscalizadora recayó totalmente en la municipalidad" (Vidaurre, 2005; Salinas, 2005; Torres, 2005; Puente, 2005). Posterior a la definición de necesidades junto a la comunidad, el aparato burocrático municipal "gerenció" y/o "gestionó" los recursos para buscar las soluciones más adecuadas, o por lo menos las que más se acercaban a los problemas expresados por la comunidad. En la elaboración del PLADECO no se observó mayor inclusión de ciudadanos ni menos aún control, fiscalización y seguimiento de ellos sobre los proyectos 
definidos junto al municipio. Incluso, actores políticos, sociales y burocráticos coincidieron en que "muchas de las necesidades y problemas detectados en la elaboración del PLADECO no se transformaron posteriormente en proyectos locales" (Torres, 2005; Núñez, 2005; Campos, 2005; Fernández, 2005).

\section{Participación ciudadana en el presupuesto participativo}

Por su parte, en los mismos municipios la participación ciudadana en los presupuestos participativos se concentró en la definición de proyectos y en el control y la fiscalización ciudadana sobre la gestión municipal. Este tipo de participación ciudadana se podría caracterizar como decisoria.

Por ejemplo, en la comuna de Illapel el proceso comienza en abril con actividades informativas; posteriormente, desde agosto hasta septiembre el municipio, junto a los representantes de la comunidad, deliberan y definen las principales necesidades y problemas de la comuna (Dirección de Desarrollo Comunitario, Illapel, 2005b: 1). El control y la fiscalización ciudadana se expresan durante todo el proceso a través de la comisión de seguimiento que "se reúne durante los meses de agosto y noviembre para revisar la situación de los compromisos adquiridos en relación a las demandas de la comunidad y adoptar medidas para asegurar su cumplimiento" (Dirección de Desarrollo Comunitario, Illapel, 2005b: 2). La instancia está integrada por el alcalde, los concejales, seis unidades municipales, seis consejeros ciudadanos del presupuesto participativo, presidentes de las uniones comunales de juntas de vecinos y un representante de los trabajadores municipales (Dirección de Desarrollo Comunitario, Illapel, 2005b: 3). Así fue como esta instancia ejerciendo su función fiscalizadora "Iogró modificar el destino de recursos fiscales del nivel provincial de gobierno a través de un proyecto del Servicio de Vialidad" (Vidaurre, 2005). El caso en cuestión se refiere al camino rural de Illapel a la localidad Ilamada "Cárcamo" que después se extendió hasta Huyntil (Vidaurre, 2005).

Para el caso de Negrete también se conformó una "comisión de seguimiento" que surgió del consejo del presupuesto participativo y está integrada por ciudadanos y funcionarios municipales y cumple la misma función fiscalizadora que en Illapel (Van Jentschyk, 2005; Díaz, Claudia, 2005). En ambos casos la comisión de seguimiento funciona sin problemas.

Una situación diferente de control y fiscalización ciudadana se generó en el municipio de Buin. En esta comuna quienes ejecutan los proyectos aprobados y priorizados por la comunidad son las propias organizaciones sociales beneficiarias y no el municipio (Dirección Desarrollo Comunitario, Buin, 2005: 2). Ellas reciben los dineros municipales y "se encargan de contratar los servicios y controlar que la ejecución de los proyectos se cumpla frente a los plazos convenidos con la municipalidad" (Salinas, 2005). La municipalidad generó reglas del juego e incentivos para otorgarle sustentabilidad a esta modalidad, ya que "si una organización social no utiliza adecuadamente los recursos fiscales es sancionada por la municipalidad y queda imposibilitada de participar en los proyectos participativos de los años venideros" (Salinas, 2005).

En el caso de San Joaquín, esta comisión existe formalmente y está indicada en el artículo 12, inciso $\mathrm{B}$, del reglamento del presupuesto participativo de este municipio, pero en la práctica ha presentado ciertos inconvenientes para cumplir su función. Por ejemplo, el club deportivo San Carlitos el año 2004 se adjudicó mediante el presupuesto participativo el techo de la cancha de babyfutbol o fútbol 5 . En la ejecución de este proyecto, los vecinos se dieron cuenta que la 
iluminación de la cancha de fútbol se estaba construyendo sobre el techo y, como consecuencia, por la noche no se podría jugar. Esta situación se la hicieron saber a los encargados municipales y al contratista encargado de la obra, pero no fueron escuchados a tiempo; como consecuencia, la municipalidad deberá invertir dinero adicional para corregir el "error técnico" (Soto, 2005).

En el caso de Cerro Navia la fiscalización ciudadana no se realiza a través de las comisiones mencionadas anteriormente, sino que está contemplada en las asambleas territoriales (Maluenda, 2005). En este caso, no se manifiesta con tanta intensidad un control por parte de la ciudadanía sobre la calidad, eficacia y eficiencia de los proyectos participativos, porque en la práctica en las asambleas territoriales no se ejerce esta función fiscalizadora. En este caso la fiscalización es hecha por los delegados del presupuesto participativo en las asambleas y en diálogo abierto con los encargados municipales, pero sólo cuando se detecta algún error evidente, es decir, se genera una fiscalización reactiva y no proactiva como en los casos de Negrete, Illapel y Buin (Maluenda, 2005).

En cuanto a la modalidad de definición de las prioridades, en los cinco casos de presupuesto participativo la definición es realizada por ciudadanos sin necesidad de ejercer cargos dirigenciales. En todos los casos, la prioridad de necesidades se realiza a través de votaciones que se ejecutan al momento de realizar la gran asamblea comunal, la cual es precedida por un promedio mínimo de tres asambleas territoriales de carácter deliberativo. En ellas se jerarquizan necesidades y se convoca a todos los representantes y ciudadanos de los territorios ${ }^{15}$. La votación sobre proyectos se realiza en las asambleas deliberativas, a través de votaciones secretas o a mano alzada (Secretaría de Planificación Comunal de San Joaquín, 2005; Dirección de Desarrollo Comunitario de Buin, 2005; Dirección de Desarrollo Comunitario de Illapel, 2005a; Díaz, Claudia, 2005; Maluenda, 2005).

Como consecuencia, en los presupuestos participativos la participación ciudadana se instaló en el diagnóstico, definición de proyectos y, bajo distintas modalidades e intensidades, en la fiscalización de los proyectos locales.

No obstante, también se puede apreciar que la fiscalización ciudadana tuvo distintas intensidades entre los municipios que implementaron presupuesto participativo. Ambas situaciones, la diferencia entre el pladeco y el presupuesto participativo y la diferencia entre la implementación de presupuestos participativos, se abordan en adelante.

\section{VI. ¿QUÉ FACTORES EXPLICAN LA PARTICIPACIÓN CIUDADANA EN LOS PRESUPUESTOS PARTICIPATIVOS?}

\section{Origen endógeno del presupuesto participativo}

Existe una diferencia sustantiva entre el origen de la ejecución del PLADECO y de los presupuestos participativos. Para el caso del PLADECO, el origen es exógeno, es decir, estuvo marcado por

15 Todos los casos de presupuesto participativo incluyen dentro de su metodología la división de la comuna en territorios, ya sea por historia o afinidad organizativa. El territorio subcomunal es la unidad básica para comenzar el trabajo informativo y concluir posteriormente el trabajo deliberativo. 
dos aspectos externos a una iniciativa de actores locales. En los casos de Cerro Navia y San Joaquín, existió un incentivo monetario para la elaboración del PLADECO, ya que el Estado a través del programa PROFIM consideró la transferencia de recursos e instrumentos de gestión a los municipios que se incorporaron al proceso de modernización municipal (Torres, 2005). El segundo aspecto es la obligatoriedad que le da la ley orgánica de municipalidades a la implementación del PLADECO, ya que si no contaban con dicho plan, esto se podía transformar en motivo suficiente para destituir del cargo al alcalde, según el artículo 3 de la Ley 18.695 Orgánica de Municipalidades (Subdere, 2002). En ambos casos la elaboración del PLADECO fue realizada por incentivos externos.

Para el caso de los presupuestos participativos, el origen es endógeno, es decir, la iniciativa provino del municipio y en cuatro de los casos específicamente por iniciativa del alcalde (Cerro Navia, Buin, San Joaquín y Negrete). En el caso de Illapel, la iniciativa la propuso la Unión Comunal de Juntas de Vecinos Rurales (Vidaurre, 2005).

Este aspecto endógeno del presupuesto participativo ha logrado que los ciudadanos se apropien de este instrumento de gestión y lo sientan como una iniciativa totalmente local, llegando en algunos casos a plantear que "si algún organismo central o regional quisiera participar de la iniciativa, sería perjudicial para el presupuesto participativo, porque los intereses de estos organismos no serían locales y comunales, sino que responderían a otros intereses" (Fernández, 2005; Gálvez, 2005; Van Jentschyk, 2005). Esta apropiación ciudadana se intensifica mucho más cuando la iniciativa surge en la comunidad y no en el alcalde, como ocurrió en el caso de Illapel. En esta comuna la modalidad de presupuesto participativo fue propuesta por la Unión Comunal de Juntas de Vecinos Rurales, quienes pidieron al municipio y al alcalde "hacer las cosas de manera distinta", exigiendo nuevos espacios y modalidades para involucrarse en la gestión municipal (Vidaurre, 2005). Este hecho ha provocado que en Illapel el presupuesto participativo esté instalado y arraigado principalmente en la ciudadanía y sus organizaciones, haciendo que la comunidad genere constantes presiones al municipio para su configuración. Así fue como la comunidad en agosto de 2005 logró que el presupuesto participativo se transforme en parte de la ordenanza municipal y pase a llamarse gestión municipal participativa (Dirección de Desarrollo Comunitario, Illapel, 2005c: 2).

El origen por iniciativa de los alcaldes de Buin, Negrete, San Joaquín y Cerro Navia se puede explicar por su militancia política. Estos alcaldes vinculados al Partido Socialista (PS) y al Partido por la Democracia (PPD) habían participado previamente en capacitaciones sobre presupuestos participativos, ofrecida por sus partidos políticos o por fundaciones sin fines de lucro vinculadas a la Concertación de Partidos por la Democracia, y en específico a la corriente más progresista de esta coalición (Pagliai, 2005).

En el caso de Illapel el origen en la comunidad se puede explicar, porque la Unión Comunal de Juntas de Vecinos Rurales el año 2002 recibió capacitación por parte de la ONG local Confluencia. Esta ONG, entre otras cosas, mostró a los dirigentes sociales la experiencia del presupuesto participativo de Porto Alegre (Vidaurre, 2005).

En los casos donde el presupuesto participativo se originó por iniciativa del alcalde -Cerro Navia, San Joaquín, Buin y Negrete- se observa que los actores sociales se apropian de la iniciativa, pero aún asumen un rol de "invitados y/o convocados" a participar de una actividad que la asocian como privativa del municipio y en particular del alcalde. Esta situación agrega un riesgo de 
perdurabilidad en el tiempo al presupuesto participativo, ya que, al estar situado excesivamente en la figura edilicia, queda la sensación entre los dirigentes sociales de que "si el alcalde cambia, esta modalidad se termina, porque puede venir otro alcalde que no continúe con esta iniciativa" (Campos, 2005; Viveros, 2005; Yañez, 2005; Puente, 2005). Situación opuesta ocurre con los dirigentes sociales de Illapel, ya que se encuentran convencidos de que "el alcalde que venga deberá continuar con esta modalidad, ya que la gente y ellos como dirigentes lo van a exigir" (Manquel, 2005; Araya, 2005; López, 2005).

\section{Del aislamiento del PLADECO a la articulación burocrática del presupuesto participativo}

A diferencia del PLADECO, que desde su elaboración hasta su implementación, se encontró situado en una unidad municipal específica, ya sea en la Secretaría Comunal de Planificación (SECPLAC) o en la Dideco, el presupuesto participativo logró incorporar a diferentes unidades municipales, como finanzas, obras municipales, desarrollo comunitario, administración municipal, secretaría de planificación, organizaciones comunitarias, entre otras. En estos casos, el éxito o fracaso del presupuesto participativo fue visto como un producto de la articulación y del trabajo coordinado de los funcionarios municipales con la comunidad, cuestión que requería en primera instancia la articulación y trabajo coordinado entre los propios funcionarios municipales (Salinas, 2005; Sánchez, 2005; Gálvez, 2005; Díaz, Claudia, 2005). No obstante, este proceso ha tenido diferentes ritmos entre los casos de presupuesto participativo.

Por ejemplo, en el caso de Cerro Navia el proceso de incorporación de los funcionarios municipales al presupuesto participativo ha sido más difícil y lento, ya que participa sólo la unidad de organizaciones comunitarias (Maluenda, 2005). En San Joaquín, participan activamente solo dos unidades municipales: la Dirección de Desarrollo Comunitario y la Secplac (Sánchez, 2005). En Buin participan cuatro unidades municipales, mientras que en Illapel y Negrete participa la mayoría de sus unidades: Obras, Secplac, Dideco, Administración Municipal, Finanzas, Departamento de Salud y Educación (Díaz, María, 2005; Gálvez, 2005; Dirección de Desarrollo Comunitario de Illapel, 2005b: 2)

En el municipio de Cerro Navia la escasa participación de funcionarios municipales ha sido criticada por los dirigentes sociales, quienes señalan que "el presupuesto participativo es una modalidad de gestión que pertenece solamente a esta unidad y no a la gestión municipal propiamente tal" (Gallardo, 2005; Yañez, 2005). Esto entorpece el proceso y lo hace más lento, incluso en ocasiones cuando los dirigentes sociales visitan alguna unidad municipal distinta de organizaciones comunitarias para realizar alguna consulta sobre los proyectos participativos, "éstas unidades municipales ni siquiera están enteradas de los proyectos participativos” (Maluenda, 2005; Yañez, 2005).

Esta diferencia en la participación de funcionarios y unidades municipales entre los casos de presupuesto participativo estuvo determinada por tres factores fundamentales: la ruralidad, el volumen del municipio y la cantidad de habitantes. Por ejemplo, en Cerro Navia y San Joaquín, municipios urbanos, con gran cantidad de población y gran cantidad de funcionarios municipales, se han logrado sumar una y dos unidades municipales respectivamente. En el municipio de Buin, más pequeño que los anteriores y con un indicador considerable de ruralidad, la participación de funcionarios municipales ha sido mayor y se ha logrado incorporar activamente a cuatro unidades municipales (Salinas, 2005). 
En Illapel y Negrete, casos que presentan los indicadores más altos de ruralidad, una reducida cantidad de habitantes y escasa cantidad de trabajadores municipales participan en la mayoría de las unidades municipales (Díaz, Claudia, 2005; Gálvez, 2005). En la última versión de presupuesto participativo en Illapel participó un $20 \%$ del total de funcionarios municipales y para el caso de Negrete la participación de funcionarios municipales alcanzó al $90 \%$ del total de trabajadores municipales (Jaque, 2005).

La característica común de Illapel y Negrete es que se trata de municipios pequeños y con una dotación de funcionarios municipales reducida en comparación a la media nacional y a los demás casos de presupuesto participativo (ver tabla 3). En estos casos, las relaciones laborales se hicieron mucho más fluidas y existió más interacción entre los funcionarios municipales, y de ellos con la comunidad y ciudadanos. Las relaciones cotidianas en estos espacios locales cobraron relevancia, ya que los funcionarios municipales manifestaron que muchos de ellos viven hace bastantes años en la comuna, trabajan por mucho tiempo en la municipalidad y conocen a todos los dirigentes sociales y a las personas que van a las asambleas; "esto ayudó para que las cosas se hicieran mejor y se facilitara la participación de funcionarios municipales y la relación de ellos con la comunidad se hiciera más expedita y sea más de igual a igual" (Jaque, 2005; Gálvez, 2005; Díaz, María, 2005).

Como contrapartida, el argumento que se ha dado en San Joaquín y Cerro Navia, es que "se ha hecho muy difícil poder reunir a los jefes de servicios municipales en torno al presupuesto participativo, ya que algunos ni siquiera se conocen" (Maluenda, 2005; Sánchez, 2005)

La ruralidad y la pobreza de los municipios en sí mismas no representan las variables explicativas, sino que ambos factores implican que los funcionarios municipales de Illapel y Negrete cotidianamente realicen mucho más trabajo de terreno en el sector rural, donde está concentrada la mayoría de la población más pobre de la comuna. En estas visitas a terreno, generalmente salen en conjunto más de dos unidades municipales, este fenómeno contribuye a que en estos casos exista una previa interacción y diálogo entre los encargados y trabajadores de estas unidades municipales, cuestión que se ha visto reflejada en la rápida incorporación al trabajo coordinado entre unidades municipales que implica el presupuesto participativo.

\section{De la labor directiva a la labor articuladora del municipio}

Los actores participantes en el presupuesto participativo y el PLADECO se pueden agrupar en tres categorías. El actor social (ciudadanos y organizaciones sociales), el actor político (alcalde y concejales) y el actor burocrático (funcionarios municipales).

En el PLADECO -aun tomando parte en él los mismos tipos de actores- el rol que cumplió el municipio se puede caracterizar como directivo, es decir, el municipio unilateralmente convocó, estableció los tiempos y las reglas del juego que determinaron la dinámica y la modalidad que adoptó la participación ciudadana, adquiriendo en ocasiones características de autosuficiencia y escasas señales de interdependencia con otros actores locales. Incluso, en los cinco casos la mesa técnica cobró mucha relevancia por sobre el municipio, la comunidad y los líderes políticos, los criterios técnicos estaban por sobre las prioridades y necesidades planteadas por la comunidad. 
Como consecuencia "no existió la posibilidad ni los espacios para hacer interactuar a estos actores" (Torres, 2005). Incluso, esta mesa técnica determinó los tiempos y niveles de participación de la comunidad en el plan y fue visto por el resto de los actores, ciudadanos, dirigentes sociales, funcionarios municipales y concejales como "una modalidad de gestión que funcionó y se mantuvo gracias a esta instancia" (Vidaurre, 2005; Van Jentschyk, 2005; Pagliai, 2005).

Por su parte, en los casos de presupuesto participativo la función del municipio fue de articulador de ciudadanos con actores políticos, sociales y burocráticos; esta articulación se reflejó en los acuerdos y las reglas del juego que rigen la participación de los actores en el proceso. Por ejemplo, "para la elaboración de la ordenanza municipal de participación ciudadana en Illapel y para la elaboración del reglamento del presupuesto participativo en Negrete participaron dirigentes sociales, políticos y funcionarios municipales" (Vidaurre, 2005; Díaz, Claudia, 2005).

Sin embargo, este proceso de articulación nuevamente se manifestó con mayor intensidad entre los casos de presupuesto participativo de Illapel y Negrete. En estos casos la articulación de actores se tradujo en que efectivamente las asambleas territoriales deliberaron y las comisiones de seguimiento fiscalizaron ${ }^{16}$; recordemos que para los casos de Cerro Navia y San Joaquín existieron mayores dificultades para ejercer esta función fiscalizadora.

En Illapel y Negrete se facilitaron y privilegiaron la interacción, el diálogo y la deliberación para definir los proyectos; las interacciones tendieron a ser más horizontales, porque las relaciones interpersonales y los contactos directos cara a cara fueron más fluidos y cobraron mayor relevancia a la hora de tomar un acuerdo que le de dirección a la gestión municipal. Esto hizo mucho más intensa y cercana la interacción de la comunidad con el municipio, ya que todos los actores participantes (independiente de su naturaleza) en su mayoría se conocían previamente.

Este fenómeno facilitó que los participantes tomaran parte activa en el proceso de decisión, ya que fue en estos casos donde la fiscalización ciudadana se hizo más efectiva y se presentó como un fenómeno de carácter eminentemente cotidiano, endógeno y local. En ellos las relaciones interpersonales se tornaron mucho más próximas que distantes, las relaciones cara a cara fueron relevantes a la hora de cumplir los compromisos adquiridos, los vecinos manifestaban que conocían muy bien las necesidades de su sector y las necesidades de los demás sectores de su comuna; por eso al encontrar los espacios para tomar parte activa en la decisión, se transformaron en protagonistas para denotar procesos participativos y fiscalizadores.

Por lo tanto, en estos casos el estilo y dinámica de la participación ciudadana se relacionaron con el rol de mediador y articulador del municipio, pero también con las características del entorno territorial, aspectos que determinaron la calidad de las interacciones que establecieron sus actores locales. las dinámicas de intercambio, diálogo y negociación de intereses entre los actores participantes. 


\section{VII.CONCLUSIONES}

La participación ciudadana en los presupuestos participativos se concentró fundamentalmente en el control y la fiscalización ciudadana de la gestión municipal, a diferencia del PLADECO que se concentró en el nivel de diagnóstico. Esta participación fue alcanzada por los cinco municipios, a pesar de las limitaciones y escasas atribuciones legales con las que cuentan todos los municipios chilenos. En estos casos, el surgimiento de las iniciativas participativas tuvo relación con un cambio local en el estilo de gestión de los municipios liderado por los alcaldes, cambio que fue por motivaciones político/partidistas, y en el de Illapel, producto de la petición de la propia comunidad.

Lo esencial que demuestran estos casos es que la participación ciudadana a nivel de la fiscalización en la gestión municipal no depende necesariamente de más atribuciones, o producto de una petición explícita de organismos del nivel central para que los municipios la incorporen, o a raíz de transferencias de recursos fiscales que la incentiven, sino que depende fundamentalmente de la necesidad política que visualicen los alcaldes junto a su equipo burocrático por mostrar un estilo de gestión distinto y renovador ante la comunidad local, cuestión que también puede ser a la inversa, es decir, que es la propia comunidad quien plantea la renovación en la gestión local. Como sea su origen, también se demuestra que el buen desarrollo de estos procesos exige un estilo de gestión articulado y sinérgico entre los actores políticos, burocráticos y sociales y que, por cierto, puede verse fortalecido con mayores atribuciones provistas por el nivel central.

Aun cuando los casos resultan ser demasiado aislados como para generalizar los resultados y que no se resuelve el tema de la discrecionalidad de los alcaldes para iniciar esta "renovación en la gestión", se puede plantear genéricamente que una reforma municipal, que persiga eficiencia y democracia por medio de mayores transferencias políticas, fiscales y administrativas, no debiera ser pensada como un proceso homogéneo de arriba hacia abajo, sino más bien como un proceso heterogéneo de apertura democrática que va de abajo hacia arriba.

Como una forma de contrarrestar la discrecionalidad de los alcaldes para iniciar estos procesos, el nivel central debiera cumplir un rol de monitoreo del cumplimiento de los objetivos democráticos a nivel municipal, pero el ritmo de transferencias fiscales, políticas y administrativas que persigan el fortalecimiento democrático de las sociedades locales lo van marcando los propios municipios, es decir, se diseña de "abajo hacia arriba”.

Tal diseño de las transferencias se plantea, porque la apertura democrática de estos municipios implicó una nueva relación entre los actores locales, relación que no se puede construir por decreto de manera homogénea a lo largo del país. En los casos en cuestión se observó que es una relación de carácter más horizontal donde las decisiones finales sobre los proyectos locales a implementar fueron consensuadas y no fueron tomadas solamente por el alcalde, o por la mesa técnica creada para tal efecto. Cuando los municipios asumieron este rol político, local, participativo, mediador y articulador, las reglas del juego que orientaban la gestión local tendieron a ser pactadas entre los actores sociales, políticos y burocráticos, lo cual abrió las puertas para que los ciudadanos no detuvieran su participación en la definición de proyectos, sino que lograran avanzar hacia el control de la gestión municipal, aspecto que hizo que las iniciativas sean más duraderas en el tiempo. 
Esta nueva relación de actores en el ámbito local también implicó que el concepto de autoridad municipal se desligara de la capacidad para imponer decisiones y regular la planificación local desde el municipio al resto de los actores. Más bien, este estilo de gestión se orientó por la idea de un gobierno local relacional, donde el municipio cumplió un rol que entendió la gestión municipal en términos de deliberación e implicación ciudadana pluralista en las decisiones públicas, desde el diagnóstico hasta la fiscalización de la gestión.

Las condiciones en las cuales se produjo esta apertura y cambio también tuvieron relación con las características territoriales de los municipios, ya que donde se alcanzaron mayores niveles de participación y articulación entre los actores locales fue en territorios rurales de pequeña escala que contaban con una historia previa de organización social. En estos espacios locales se generaron más fácilmente los procesos participativos; las interacciones que se generaron se caracterizaron por ser en su mayoría de carácter consensual y no directivas, se privilegiaron el diálogo, la confianza entre actores y la deliberación para solucionar las principales dificultades que se provocaron a la hora de definir prioridades y proyectos a financiar por los fondos participativos; esto hizo que una gran cantidad de los actores tomaran parte activa en el proceso de decisión.

De esa forma, se puede concluir que, a pesar de lo centralizado que resulta ser el diseño institucional subnacional chileno, la participación ciudadana en la gestión municipal, o por lo menos la que se expresó en los presupuestos participativos, no estuvo determinada necesariamente por incentivos institucionales gubernamentales del nivel central, sino más bien estuvo dada por aspectos políticos, endógenos y locales, los cuales implicaron la adopción de una función deliberadora de la municipalidad, variables que se manifestaron más intensamente en municipios de pequeña escala.

\section{REFERENCIAS}

Araya, Juan. 2005. Representante ciudadano del presupuesto participativo de Illapel. Entrevista realizada el 07/07/05. Asociación Chilena de Municipalidades. 2005. "Entrevista a Michelle Bachelet”. Revista Municipio Autónomo, edición especial $\mathrm{N}^{\circ} 11$ (noviembre): 4-5.

Asociación Chilena de Municipalidades. 2006. "Semana Municipal del 27 de marzo al 2 de abril del 2006". Boletín Semanal No 13: 2.

Bardhan, Pranab. 2002. "Decentralization of governance and development". Journal of Economics Perspectives 16 (4): 185-205.

Blanco, Carlos y Allan Brewer-Carias. 1997. Gobernabilidad y desarrollo democrático en América Latina. Nueva Cork: PNUD.

Blanco, Ismael y Ricard Gomá. 2002a . "Proximidad y participación: marco conceptual y presentación de experiencias". En Gobiernos locales y redes participativas, editado por Ismael Blanco y Ricard Gomá (coord.). Barcelona: Editorial Ariel, 23-25.

Blanco, Ismael y Ricard Gomá. 2002b. "Presupuestos participativos y democracia local: una comparación entre las experiencias españolas y brasileñas". Biblioteca Virtual TOP http: //www.top.org.ar/publicac.htm

Campos, Francisca. 2005. Delegada rural del presupuesto participativo de Negrete. Entrevista realizada el 07/09/05.

Carrillo, Jesús. 2003. "Descentralización y buen gobierno en Colombia”. En Visión Institucional de los Gobiernos Locales en Colombia, editada por Jesús Carrillo. Tesis de doctorado en Ciencias Políticas y Sociales de la UNAM, 27-30.

Comité Interministerial de Modernización de la Gestión Pública. 2000. El Estado al Servicio de la Gente. Balance 19942000. Santiago: Comité Interministerial de Modernización de la Gestión Pública.

Delamaza, Gonzalo; Margarita Fernández et al. 2004. Innovación y ciudadanía en la gestión territorial: el rol de los municipios. Santiago: Programa de Innovación y Ciudadanía. 
Díaz, Claudia. 2005. Administradora Municipal de la Municipalidad de Negrete. Entrevista realizada el 07/09/05.

Díaz, María. 2005. Concejala de la comuna de Illapel. Entrevista realizada el 07/07/05.

Dirección de Desarrollo Comunitario, Municipio de Illapel. 2005a. Cronograma del Presupuesto Participativo de Illapel. Illapel, Chile: Municipalidad de Illapel.

Dirección de Desarrollo Comunitario, Municipio de Illapel. 2005b. Reglamento del Presupuesto Participativo de Illapel. Illapel, Chile: Municipalidad de Illapel.

Dirección de Desarrollo Comunitario, Municipio de Illapel. 2005c. Acta de acuerdos del concejo municipal en relación a la modificación de la ordenanza municipal de participación ciudadana. Illapel, Chile: Municipalidad de Illapel.

Dirección de Desarrollo Comunitario, Municipio de Buin. 2005. Reglamento del Presupuesto Participativo de Buin. Concepto y Generalidades. Buin, Chile: Municipalidad de Buin.

Fernández, Lucía. 2005. Representante ciudadano del presupuesto participativo de Buin. Entrevista realizada el día 02/08/05.

Finot, Iván. 1998. “Descentralización del estado y participación Ciudadana en América Latina. Un enfoque crítico”. CEPAL, LC/IP/R165: 1-24.

Finot, Iván. 1999. “Elementos para una reorientación de las políticas de descentralización y participación en América Latina". Reforma y Democracia CLAD 15: 71-110.

Finot, Iván. 2001. Descentralización en América Latina: teoría y práctica. Santiago: ILPES/CEPAL.

Finot, Iván. 2003. “Descentralización y Participación en América Latina: Una mirada desde la economía”. Revista de la CEPAL No 78: 139-149.

Frei, Gonzalo. 2005. Asesor de la División de Municipalidades de la Subsecretaría de Desarrollo Regional y Administrativo de Chile. Entrevista realizada el 04/06/06.

Gálvez, Amara. 2005. Directora de Desarrollo Comunitario de la Municipalidad de Illapel. Entrevista realizada el 08/07/05.

Gallardo, José. 2005. Dirigente Social de Cerro Navia. Entrevista realizada el día 14/09/05.

García-Guadilla, Maria. 2002. “Democracy, Decentralization and Clientelism: New Relationships and Old Practices”. Latin American Perspectives 29 (5): 90-109.

Huerta, María, Carlos Pressaco, Consuelo Ahumada, Marcela Velasco, Jesús Puente y Juan Molina. 2000. Descentralización, Municipio y participación ciudadana: Chile, Colombia y Guatemala. Bogotá: Centro Editorial Javeriano CEJA.

Jaque, Pedro. 2005. Presidente de la Asociación de Funcionarios Municipales de la Municipalidad de Negrete. Entrevista realizada el 08/09/05.

López, Eduardo. 2005. Presidente de la Junta de Vecinos “La Colonia” y Relacionador Público de la Unión Comunal de Juntas de Vecinos Rurales y Consejero del Presupuesto Participativo. Entrevista realizada el 08/07/05.

Manquel, Hermosinda. 2005. Consejera del Presupuesto Participativo, representante del territorio Cus-Cus de IIlapel. Entrevista realizada el 07/07/05.

Maluenda, Alex. 2005. Encargado de la oficina de Organizaciones Comunitarias de la Municipalidad de Cerro Navia. Entrevista realizada el día 30/06/05.

Mardones, Rodrigo. 2006. “Descentralización y Transición en Chile”. Revista de Ciencia Política 26 (1): 3-24.

Márquez, Francisca, Andrea Sanhueza et al. 2001. Participación Ciudadana en la Gestión Pública. Marco Conceptual. Santiago: Ministerio Secretaría General de la Presidencia, Gobierno de Chile.

Matías, Domingo. 2004. Presupuesto Participativo y democratización. Santo Domingo: Programa de Apoyo a la Reforma y Modernización del Estado.

Montecinos, Egon. 2005. “Los estudios de descentralización en América Latina: Una revisión sobre el estado actual de la temática". Revista EURE XXXI (93): 77-88.

Montero, Alfred y David Samuels. 2004. "The Political Determinants of Decentralization in Latin American: Causes and Consequences". En Decentralization and Democracy in Latin America, editado por Alfred Montero y Samuels David (comps.). Indiana: University of Notre Dame Press, Notre Dame, 3-32.

Nickson, Andrew. 1998. "Tendencias actuales de las finanzas locales en América Latina”. Revista Reforma y Democracia $\mathrm{N}^{\circ} 12: 71-88$.

Nickson, Andrew. 2003. "Descentralización política”. Ponencia presentada en el seminario internacional Logros y desafíos de la descentralización en América Latina 4 y 5 de septiembre de 2003 organizado por el Centro Boliviano de Estudios Multidisciplinarios CEBEM, La Paz.

Núñez, Jenny. 2005. Concejal de la Municipalidad de San Joaquín. Entrevista realizada el 18/08/05.

Nylen, William. 2002. "Testing the Empowerment Thesis: The Participatory Budget in Belo Horizonte and Betim, Brazil". Comparative Politics 34 (2): 127-145.

Nylen, William. 2003. Participatory Democracy Versus Elitist Democracy: Lessons from Brazil. New York: Palgrave Macmillan.

0’Neill, Kathleen. 2003. “Decentralization as an Electoral Strategy”. Comparative Political Studies 36 (9): 1068-1091. 
Pagliai César. 2005. Sistematización de la experiencia de presupuesto participativo en Cerro Navia. Documento de Trabajo.

Puente, Gabriel. 2005. Presidente de la Unión Comunal de Juntas de Vecinos de Buin. Entrevista realizada el día 02/08/05.

Ramírez, Álvaro. 2001. Modernización de la gestión Pública. El caso Chileno (1994-2000). Estudio de Caso Número 58. Santiago: Universidad de Chile.

Rojas, Fernando. 1999. "The Political Context of Decentralization in Latin American: Accounting for the Particular Demands of Decentralization in the Region". En Annual Wordl Bank Conference on Development in Latin Americanand the Caribbean, editado por Shahid Javed Burki y Guillermo Perry. Washington: The World Bank, 9-31. http: //wbln0018.worldbank.org/LAC/lacinfoclient.nsf/d29684951174975c85256735007fef12/ b593afa08932cdba8525690b006d291e

Salinas Juan. 2005. Director de Desarrollo Comunitario de la Municipalidad de Buin. Entrevistas realizadas los días 10, 14 y 23 de junio 2005.

Sánchez, Gerardo. 2005. Secretario de Planificación Comunal de la Municipalidad de San Joaquín. Entrevista realizada el 17/08/05.

Secretaria de Planificación Comunal, Municipio de San Joaquín. 2005. Reglamento del presupuesto participativo año 2005 de la ilustre municipalidad de San Joaquín. San Joaquín, Chile: Municipio de San Joaquín.

Shack, Nelson. 2005. "La programación participativa del presupuesto participativo en Perú: primeras lecciones de un proceso de concertación". Reforma y Democracia №32: 131-158.

Sintomer, Ives. 2005. "Los presupuestos participativos en Europa: retos y Desafíos". Reforma y Democracia № 31 : 63-92.

Soto, Atilio. 2005. Delegado del presupuesto participativo de San Joaquín. Entrevista realizada el 23/08/05.

Subsecretaría de Desarrollo Regional, SUBDERE. 1999. PROFIM I y I/ Construyendo Juntos el Nuevo Municipio. Santiago División de Municipalidades.

Subsecretaría de Desarrollo Regional, SUBDERE. 2002. Ley 18.695 Orgánica Constitucional de Municipalidades (Texto refundido, actualizado y sistematizado). Santiago: Ministerio del Interior.

Subsecretaria de Desarrollo Regional, SUBDERE. 2003. Participación Ciudadana en la Gestión de Gobiernos Regionales y Municipios: Diagnóstico y Situación Actual. Documento de Trabajo, División de Políticas. Santiago.

Torres, Gloria. 2005. Encargada del programa de Buenas Prácticas Municipales de la Subsecretaría de Desarrollo Regional y Administrativo. Entrevista realizada los días 15 y 22 de junio de 2005.

Van Jentschyk, Edwin. 2005. Alcalde de la Municipalidad de Negrete. Entrevista realizada el 08/09/05.

Vidaurre, Gerardo. 2005. Director Ejecutivo de ONG Confluencia de la comuna de Illapel. Entrevista realizada el día 10/07/05.

Viveros Carmen. 2005. Tesorera de la Junta de Vecinos número 10 y consejera del presupuesto participativo en San Joaquín. Entrevista realizada el 24/08/05.

Waissbluth, Mario. 2005. "La Reforma del Estado en Chile 1990-2005. Diagnósticos y Propuestas de Futuro". Serie Gestión N 76: 3-114.

Whitford, Andrew. 2002. "Decentralization and Political Control of the Burocracy". Journal of Theoretical Politics 14 (2): 167-193.

Willis, Eliza, Christopher Garman y Stephan Haggard. 1999. "The Politics of Decentralization in Latin American”. Latin American Research Review 34 (1): 7-50.

Willis, Eliza, Christopher Garman y Stephan Haggard. 2001. "Fiscal Decentralization: A political Theory with Latin American Cases". Journal Word Politics 53 (2): 205-236.

Yáñez, Margarita. 2005. Delegada del Presupuesto Participativo de Cerro Navia. Entrevista realizada el día 03/08/05.

Egon Montecinos es Doctor en Investigación en Ciencias Sociales con especialización en Ciencia Política en FLACSOMEXICO (2006). Actualmente, es investigador del Centro de Estudios del Desarrollo Regional y Local de la Universidad de Los Lagos, Osorno, Chile. Sus principales líneas de investigación son descentralización y participación ciudadana y participación ciudadana en la gestión municipal.

(E-mail: emontecinos@ulagos.cl) 